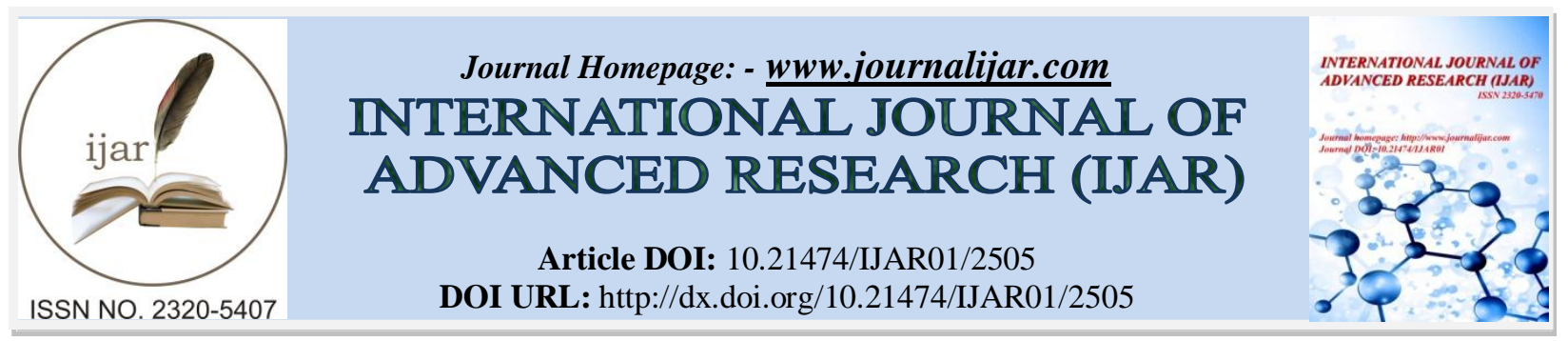

RESEARCH ARTICLE

\title{
DISTRIBUTION OF MATING TYPE ALLELES AND FERTILITY OF MAGNAPORTHE ORYZAE ISOLATES IN SOUTH INDIA.
}

"Khaled Fathy ${ }^{1}$ and Prashanthi S. K. ${ }^{2}$.

1. Genetics Department, Molecular Genetics Lab., Faculty of Agriculture, Zagazig University, 44519, Egypt.

2. Department of Biotechnology, IABT, University of Agricultural sciences, Dharward, Karnataka, 580005, India.

\section{Manuscript Info}

Manuscript History

Received: 25 October 2016

Final Accepted: 23 November 2016

Published: December 2016

Key words:-

Magnaporthe oryzae, Mating type,

Ascospores, Perithecia, South India

\section{Abstract}

Ninety seven isolates of Magnaporthe oryzae collected from different locations of south India were evaluated to understand the mating type distribution and fertility of isolates by using MAT locus specific primers, forty six isolates showed mating MAT1-1, forty two showed mating type MAT1-2, seven isolates showed hermaphrodite and two unknown mating type. The observation that both mating-types were present in the states and districts of south India, suggests the possibility of sexual recombination in nature and this can affect diversity and dissemination. Clonal reproduction and sexual recombination may be the possible reasons for the population dynamics of M. oryzae in South India. Populations showing evidence for both types mating types may be assayed for fertility using a range of tester isolates from different regions. As locally obtained hermaphrodite isolates of both mating types from this study may be used as testers for a systematic survey of local field isolates in future.

Copy Right, IJAR, 2016,. All rights reserved.

\section{Introduction:}

Magnaporthe oryzae, which causes rice blast, one of the top pathogens which has the ability to cause high level of losses in rice field. The life cycle of Magnaporthe oryzae involves both asexual and sexual reproduction. Asexual propagation can be initiated following standard laboratory procedures. Asexual spores (conidia) are easy to collect and can be used in rice or barley infection assays to evaluate virulence. Although the sexual cycle is rarely observed under field conditions, in the laboratory the sexual cycle can be induced using specific culture conditions, these are some of the characteristics that have made Magnaporthe oryzae an attractive system to perform genetic analysis and molecular biology (Valent et al., 1986).

Main sources of variation in Magnaporthe oryzae populations, high capacity of asexual reproduction, Mutation and migration (Zeigler et al., 1994). Parasexual recombination was found to be reason of variation in rice blast population even in putatively clonal populations (Zeigler et al., 1997). Sexually fertile of Magnaporthe oryzae was known to be rare and found in few areas of Southeast Asia.

Magnaporthe oryzae is a heterotallic fungus, sexual reproduction occurs when mycelia of Magnaporthe oryzae of opposite mating contact each other. Sexual recombination controlled by a single locus (MAT1) that presents two mating types MAT1-1 and MAT1-2 which are required for sexual recombination (Kang et al., 1994).

Corresponding Author: Khaled Fathy.

Address:- Genetics Department, Molecular Genetics Lab. Faculty of Agriculture, Zagazig University, 44519, Egypt. 
The fertile interactions only possible between individuals of opposite mating type designated MAT1-1 (Male fertile) and MAT1-2 (Female fertile). However, the capacity of M. grisea isolates to produce perithecia (female fertility) is apparently controlled by genes at several loci, and these segregate independently of mating type and pathogenicity on different hosts (Kolmer and Ellingboe, 1988). In Magnaporthe oryzae, meiosis is immediately followed by a single mitotic division to generate four pairs of sister ascospores grouped into a single ascus. The ascospores are formed within the sexual structures (perithecia) produced by the female-fertile strain (or by both strains if both are female-fertile). Perithecia are flask shaped bodies that carry asci-bags containing ascospores, the products of meiosis- in abundance. Asci can be dissected to liberate the ascospores, which are arranged as un ordered octads. In either case the segregation patterns of genetic markers can be readily followed and the genetic basis of phenotypic traits determined (Valent et al., 1991).

In fertility survey results were generally consistent in that female sterility was the norm, fertile isolates were typically male-fertile only, and mating type ratios were skewed (Notteghem and Silué, 1992; Yaegashi and Nishihara, 1976). This rarity of female fertility was consistent with the reported abundance of transposable elements in Magnaporthe grisea rice pathogens (Zeigler, 1998; Zeigler et al., 1994). Translocations and non homologous crossover events can result in meiotic failure. Where the environment permits long-term persistence of well-adapted asexual lineages, mutations can accumulate at loci mediating fertility and result in a predominance of infertility in populations (Kistler and Miao,1992; Zeigler, 1998). In the late 1980s, hermaphroditic isolates were used as tester strains as well as in back-crossing programs to develop fertile rice pathogens of both mating types (Chao and Ellingboe, 1991).

Hermaphroditic isolates have been reported from southern China (Chengyun et al., 1992) and the Indian Himalayas (Kumar and Zeigler, 1995). However, a study from southern India reported no sexually fertile rice pathogens (Devulapalle and Suryanarayanan, 1995; Viji and Gnanamanickam, 1998).

Mekwatanakarn et al. (1999) studied mating type distribution and sexual fertility of Magnaporthe grisea isolates collected from different locations in Thailand. Three hundred forty-one single conidium isolates of $M$. grisea collected from five sites in north, northeast, and central Thailand were evaluated in vitro for sexual fertility and mating type. Ascospores were detected in isolates which isolated from the north-eastern and northern regions. Sixty seven per cent of Magnaporthe grisea isolates were infertile when crossed with the hermaphrodite strains. In bioassay mating type, fifty to seventy five per cent of isolates showed male fertility MAT1-1 and fifty to eighty five per cent of isolates showed MAT1-2 mating type from all locations in Thailand, hermaphroditic isolates were also detected. Back crossing of Magnaporthe grisea with weeping love grass (Eragrostis curvularia) was developed to show high level of fertility (Valent et al., 1991).

Regulation of mating is controlled by a single mating type locus that contains genes that encode putative transcription factors which play role in transcription regulators of pheromone production and reception. Sexual mating compatibility in Magnaporthe oryzae is governed by the presence of two alleles of the mating type locus MAT1. The mating-type locus is found in the mating partner as an idiomorph, a non-homologues DNA sequence and gene set at the same chromosomal position. Ascogonia that are fertilized by male structures, which can be conidia, or spermatia (Metzenberg and Glass 1990; Coppin et al., 1997). MAT locus could be linked to an avirulence gene, with no compatibility with the prevailing Rice cultivar, and this could represents a drawback for fitness, being eliminated along time (Notteghem and Silué, 1992).

Mycelium tufts were observed between crossed Magnaporthe oryzae cultures, new haplotypes were found, indicating the presence of recombination (Zeigler et al., 1997). Crossing can occurs between fertile isolates, Magnaporthe oryzae isolates also found to be hermaphrodite (Zeigler, 1998).

When two Magnaporthe oryzae populations from Himalayas were analyzed, it was found that twenty two per cent of the isolates belonged to MAT1-1 and forty three per cent to MAT1-2, and hermaphrodite and male fertile isolates were found, suggesting a possible occurrence of sexual recombination in this Himalayan region. The structure of some Magnaporthe oryzae populations may be affected by sexual recombination which gives dynamic behave and diverse among populations (Kumar et al., 1999).

There was a consensus that the majority of the Magnaporthe oryzae populations lost its viability of sexual reproduction. It was proposed that only one mating type could be found when new rice cultivar was planted in a 
particular area (Zeigler, 1998). In Argentina, analysis of one hundred twenty five isolates collected between 2000 and 2003 showed that all of them belonged to mating type MAT1-1. Similar results were obtained in Korea, when the analysis of two hundred fifty four isolates demonstrated that all of them also belonged to MAT1-1 (Park et al., 2008). Twenty nine per cent isolates belongs to MAT1-1 and seventy one per cent belongs to MAT 1-2 in Africa, but none of the isolates was hermaphrodite, avoiding crossing among them (Takan et al., 2011).

DNA mobile genetic elements can cause chromosomic rearrangement and degeneration of sexual behavior without producing a drawback of fitness (Chuma et al., 2011). One role of the sexual reproduction is to form resistance structures to enable the fungi to adjust against unfavourable conditions (www.intechopen.com, Klaus, Brazil).

Populations of Magnaporthe oryzae worldwide were characterized genetically to identify sexual reproduction (Saleh et $\left.a l .2012^{\mathrm{a}}\right)$. The two mating types in one Chinese population and almost all strains were female-fertile. Viable progenies of Magnaporthe oryzae were produced in vitro, sexual reproduction in Magnaporthe oryzae population was confirmed with the help of genotypic richness and linkage disequilibrium data. Computer simulations confirmed that the observed genetic characteristics were unlikely to have arisen in the absence of recombination. The authors concluded that Magnaporthe oryzae, population reproduces sexually in nature in Southeast Asia and evidenced the loss of sexual reproduction by a fungal plant pathogen outside its centre of origin.

Mating type distribution and lineage diversity was studied; sexual recombination might be the one reason for lineage diversity in Magnaporthe oryzae in fields of rice growing regions in North-East and Eastern states of India (Imam et al., 2014).

Soma et al. (2014) studied the mating type alleles as a marker to measure population diversity in forty six isolates of Magnaporthe oryzae from various ecosystems of coastal Odisha, India. Mating types MAT1-1 and MAT1-2 was found in all the ecosystems in uplands and in irrigated fields. In irrigated ecosystem fields MAT1-1 and MAT1-2 could be found. The disease spreads was very fast in rice fields resulting in blast lesions looking as green islands was found in isolates showed MAT1-2.

\section{Materials and methods:}

\section{Analysis of mating type alleles in Magnaporthe oryzae isolates:}

In current study 97 Magnaporthe Oryzae isolates collected from different places in south India (Table 1) were studied for mating type analysis by Mat gene specific molecular markers. The pure culture of each isolate was grown in Rice straw Broth medium for approximately 8-15 days at room temperature $\left(25-28^{\circ} \mathrm{C}\right)$ to produce mycelia.

Mycelium mats of ninety seven blast isolates of Magnaporthe oryzae was used for genomic DNA isolation by adopting Cetyl Trimethyl Ammonium Bromide $\mathrm{CTAB} / \mathrm{NaCl}$ method. Agarose gel electrophoresis was done to check the quality of DNA by running on $0.8 \%$ agarose (Lonza, USA) and DNA was quantified by using Nano drop spectrophotometer (ND-1000 V3.5.2, Nano Drop Technologies Inc., USA).

\section{Amplification of MAT gene:}

Mating type genes MAT1-1 and MAT1-2 were amplified according to Wang et al. (2004) using two pairs of specific primers. MAT1-1 Forward Primer (TCAGCTCGCCCAAATCAACAAT) and Reverse primer (ACTCAAGACCCGGCACGAACAT) yield a product of 809 bp and MAT1-2 Forward Primer (GAGTTGCCTGCCCGCTTCTG) and Reverse primer (GGCTTGGTCGTTGGGGATTGT) yield a product of 940 bp. Amplifications were performed in a final volume of $20 \mu \mathrm{l}$ of reaction mixture: 10x Taq assay buffer, $2.5 \mathrm{mM}$ dNTPs, 10 picoMole for forward and reverse primers, Taq DNA polymerase XT-5 PCR system $\left(\mathrm{GeNeI}^{\mathrm{TM}}, \mathrm{Merck}\right.$ Biosciences, Bengalure) 3 units $/ \mu \mathrm{l}$, Template DNA $50 \mathrm{ng} / \mu \mathrm{l}$ and sterile distilled Millipore water. The reaction mixture was given a momentary spin for mixing of the reaction components except DNA template. Master mixture was distributed to all $0.2 \mathrm{ml}$ PCR tubes and finally $1 \mu \mathrm{l}$ of respective DNA template was added and short spin was given to mix template with all reaction components and then tubes were loaded in a thermal cycler. Thermal cycler conditions; $95^{\circ} \mathrm{C}$ Initial denaturation for $3 \mathrm{~min}$, followed by $35 \mathrm{cycles}$ of $95^{\circ} \mathrm{C}$ for $45 \mathrm{sec}$, The annealing temperature $70{ }^{\circ} \mathrm{C}$ for MAT1-1 and $71{ }^{\circ} \mathrm{C}$ for MAT1-2 for $1.45 \mathrm{~min}, 72^{\circ} \mathrm{C}$ for $2 \mathrm{~min}$ and a final extension step at $72^{\circ} \mathrm{C}$ for $7 \mathrm{~min}$. PCR reaction was carried out using Master gradient 5331- Eppendorf version 2.30.31-09, Germany. Two per cent (6 
$\mathrm{g} / 300 \mathrm{ml}$ ) agarose was added to $1 \mathrm{X}$ TAE buffer (pH-8.0) for PCR separation, Ethidium bromide $12 \mu \mathrm{l}$ was used as a staining agent. The gel was run at $8 \mathrm{~V} / \mathrm{cm}$ for 1 to 1.5 hours and bands were visualized and documented in gel documentation system (Model Alpha Imager 1200, Alpha Innotech Corp, USA). Based on the results, 97 isolates were grouped into Male fertile, Female fertile, Hermaphrodite and Unknown based on presence or absence of MAT allele. Mating type frequencies were calculated.

Table 1:- Details of Magnaporthe oryzae isolates used for molecular study

\begin{tabular}{|c|c|c|c|c|c|c|c|}
\hline SI. No. & State & District & Place of collection & Host variety & Type of blast & Geographic coordinates & Code \\
\hline 1 & Karnataka & Dharwad & A.R.S., Mugad & HR-12 & Leaf blast & $15^{\circ} 27^{\prime} \mathrm{N}, 74^{\circ} 55^{\prime} \mathrm{E} ; 687 \mathrm{~m}$ above sea level & Mo-si-105 \\
\hline 2 & Karnataka & Dharwad & A.R.S., Mugad & Intan Mugad & Leaf blast & $15^{\circ} 27^{\prime} \mathrm{N}, 74^{\circ} 55^{\prime} \mathrm{E} ; 687 \mathrm{~m}$ above sea level & Mo-si-106 \\
\hline 3 & Karnataka & Dharwad & A.R.S., Mugad & Honasu & Leaf blast & $15^{\circ} 27^{\prime} \mathrm{N}, 74^{\circ} 55^{\prime} \mathrm{E} ; 687 \mathrm{~m}$ above sea level & Mo-si-107 \\
\hline 4 & Karnataka & Dharwad & A.R.S., Mugad & Nyareminda & Leaf blast & $15^{\circ} 27^{\prime} \mathrm{N}, 74^{\circ} 55^{\prime} \mathrm{E} ; 687 \mathrm{~m}$ above sea level & Mo-si-108 \\
\hline 6 & Karnataka & Dharwad & A.R.S., Mugad & Kari Esadi & Leaf blast & $15^{\circ} 27^{\prime} \mathrm{N}, 74^{\circ} 55^{\prime} \mathrm{E} ; 687 \mathrm{~m}$ above sea level & Mo-si-110 \\
\hline 7 & Karnataka & Dharwad & A.R.S., Mugad & Pramod & Leaf blast & $15^{\circ} 27^{\prime} \mathrm{N}, 74^{\circ} 55^{\prime} \mathrm{E} ; 687 \mathrm{~m}$ above sea level & Mo-si-111 \\
\hline 8 & Karnataka & Dharwad & A.R.S., Mugad & Jeerigesanna1 & Leaf blast & $15^{\circ} 27^{\prime} \mathrm{N}, 74^{\circ} 55^{\prime} \mathrm{E} ; 687 \mathrm{~m}$ above sea level & Mo-si-112 \\
\hline 9 & Karnataka & Dharwad & A.R.S., Mugad & Jaddu batta & Leaf blast & $15^{\circ} 27^{\prime} \mathrm{N}, 74^{\circ} 55^{\prime} \mathrm{E} ; 687 \mathrm{~m}$ above sea level & Mo-si-113 \\
\hline 10 & Karnataka & Dharwad & A.R.S., Mugad & Intan & Neck blast & $15^{\circ} 27^{\prime} \mathrm{N}, 74^{\circ} 55^{\prime} \mathrm{E} ; 687 \mathrm{~m}$ above sea level & Mo-si-114 \\
\hline 11 & Karnataka & Dharwad & A.R.S., Mugad & Jirga & Leaf blast & $15^{\circ} 27^{\prime} \mathrm{N}, 74^{\circ} 55^{\prime} \mathrm{E} ; 687 \mathrm{~m}$ above sea level & Mo-si-115 \\
\hline 12 & Karnataka & Dharwad & Mugad & Intan & Leaf blast & $15^{\circ} 27^{\prime} \mathrm{N}, 74^{\circ} 55^{\prime} \mathrm{E} ; 687 \mathrm{~m}$ above sea level & Mo-si-16b \\
\hline 13 & Karnataka & Dharwad & A.R.S., Mugad & Ashoka 200F & Leaf blast & $15^{\circ} 27^{\prime} \mathrm{N}, 74^{\circ} 55^{\prime} \mathrm{E} ; 687 \mathrm{~m}$ above sea level & Mo-si-116 \\
\hline 14 & Karnataka & Dharwad & A.R.S., Mugad & Chippiga & Leaf blast & $15^{\circ} 27^{\prime} \mathrm{N}, 74^{\circ} 55^{\prime} \mathrm{E} ; 687 \mathrm{~m}$ above sea level & Mo-si-200 \\
\hline 15 & Karnataka & Dharwad & A.R.S., Mugad & Gum Kadle & Leaf blast & $15^{\circ} 27^{\prime} \mathrm{N}, 74^{\circ} 55^{\prime} \mathrm{E} ; 687 \mathrm{~m}$ above sea level & Mo-si-201 \\
\hline 16 & Karnataka & Dharwad & Mugad & Unknown & Neck blast & $15^{\circ} 27^{\prime} \mathrm{N}, 74^{\circ} 55^{\prime} \mathrm{E} ; 687 \mathrm{~m}$ above sea level & Mo-si-202 \\
\hline 17 & Karnataka & Dharwad & A.R.S., Mugad & Kempu Dodda & Leaf blast & $15^{\circ} 27^{\prime} \mathrm{N}, 74^{\circ} 55^{\prime} \mathrm{E} ; 687 \mathrm{~m}$ above sea level & Mo-si-203 \\
\hline 18 & Karnataka & Dharwad & A.R.S., Mugad & Billi Hege & Leaf blast & $15^{\circ} 27^{\prime} \mathrm{N}, 74^{\circ} 55^{\prime} \mathrm{E} ; 687 \mathrm{~m}$ above sea level & Mo-si-204 \\
\hline 19 & Karnataka & Dharwad & A.R.S., Mugad & Jondole Jeerge & Leaf blast & $15^{\circ} 27^{\prime} \mathrm{N}, 74^{\circ} 55^{\prime} \mathrm{E} ; 687 \mathrm{~m}$ above sea level & Mo-si-205 \\
\hline 20 & Karnataka & Dharwad & A.R.S., Mugad & Bangar sanna & Leaf blast & $15^{\circ} 27^{\prime} \mathrm{N}, 74^{\circ} 55^{\prime} \mathrm{E} ; 687 \mathrm{~m}$ above sea level & Mo-si-206 \\
\hline 23 & Karnataka & Dharwad & A.R.S., Mugad & BPT5204 & Neck blast & $15^{\circ} 27^{\prime} \mathrm{N}, 74^{\circ} 55^{\prime} \mathrm{E} ; 687 \mathrm{~m}$ above sea level & Mo-si-102 \\
\hline 24 & Karnataka & Dharwad & A.R.S., Mugad & Jeerige sanna-2 & Leaf blast & $15^{\circ} 27^{\prime} \mathrm{N}, 74^{\circ} 55^{\prime} \mathrm{E} ; 687 \mathrm{~m}$ above sea level & Mo-si-209 \\
\hline 25 & Karnataka & Dharwad & A.R.S., Mugad & BPT5204 & Leaf blast & $15^{\circ} 27^{\prime} \mathrm{N}, 74^{\circ} 55^{\prime} \mathrm{E} ; 687 \mathrm{~m}$ above sea level & Mo-si-210 \\
\hline 26 & Karnataka & Dharwad & A.R.S., Mugad & DHB1 & Leaf blast & $15^{\circ} 27^{\prime} \mathrm{N}, 74^{\circ} 55^{\prime} \mathrm{E} ; 687 \mathrm{~m}$ above sea level & Mo-si-99 \\
\hline 27 & Karnataka & Dharwad & A.R.S., Mugad & DHB4 & Leaf blast & $15^{\circ} 27^{\prime} \mathrm{N}, 74^{\circ} 55^{\prime} \mathrm{E} ; 687 \mathrm{~m}$ above sea level & Mo-si-100 \\
\hline 28 & Karnataka & Dharwad & Nigadi & Sali & Leaf blast & $15^{\circ} 27^{\prime} \mathrm{N}, 74^{\circ} 55^{\prime} \mathrm{E} ; 687 \mathrm{~m}$ above sea level & Mo-si-211 \\
\hline 29 & Karnataka & Kodagu & Ponnampet & Asha & Leaf blast & $12^{\circ} 12^{\prime} \mathrm{N}, 75^{\circ} 54^{\prime} \mathrm{E} ; 851 \mathrm{~m}$ above sea level & Mo-si-048 \\
\hline 30 & Karnataka & Kodagu & Ponnampet & DHB-30 & Leaf blast & $12^{\circ} 12^{\prime} \mathrm{N}, 75^{\circ} 54^{\prime} \mathrm{E} ; 851 \mathrm{~m}$ above sea level & Mo-si-117 \\
\hline 31 & Karnataka & Kodagu & Ponnampet & DHB-25 & Leaf blast & $12^{\circ} 12^{\prime} \mathrm{N}, 75^{\circ} 54^{\prime} \mathrm{E} ; 851 \mathrm{~m}$ above sea level & Mo-si-118 \\
\hline 32 & Karnataka & Kodagu & Ponnampet & Unknown & Leaf blast & $12^{\circ} 12^{\prime} \mathrm{N}, 75^{\circ} 54^{\prime} \mathrm{E} ; 851 \mathrm{~m}$ above sea level & Mo-si-119 \\
\hline 33 & Karnataka & Kodagu & Ponnampet & HR-12 & Leaf blast & $12^{\circ} 12^{\prime} \mathrm{N}, 75^{\circ} 54^{\prime} \mathrm{E} ; 851 \mathrm{~m}$ above sea level & Mo-si-120 \\
\hline 34 & Karnataka & Kodagu & Ponnampet & Mysore & Leaf blast & $12^{\circ} 12^{\prime} \mathrm{N}, 75^{\circ} 54^{\prime} \mathrm{E} ; 851 \mathrm{~m}$ above sea level & Mo-si-050 \\
\hline 35 & Karnataka & Mandya & Z.A.R.S., Mandya & NSN & Leaf blast & $12^{\circ} 31^{\prime} \mathrm{N}, 76^{\circ} 54^{\prime} \mathrm{E} ; 113 \mathrm{~m}$ above sea level & Mo-si-081 \\
\hline 36 & Karnataka & Mandya & Unknown & KMP & Neck blast & $12^{\circ} 31^{\prime} \mathrm{N}, 76^{\circ} 54^{\prime} \mathrm{E} ; 113 \mathrm{~m}$ above sea level & Mo-si-083 \\
\hline 37 & Karnataka & Mandya & Z.A.R.S., Mandya & Jaya & Leaf blast & $12^{\circ} 31^{\prime} \mathrm{N}, 76^{\circ} 54^{\prime} \mathrm{E} ; 113 \mathrm{~m}$ above sea level & Mo-si-079 \\
\hline 38 & Karnataka & Mandya & Unknown & Unknown & Neck blast & $12^{\circ} 31^{\prime} \mathrm{N}, 76^{\circ} 54^{\prime} \mathrm{E} ; 113 \mathrm{~m}$ above sea level & Mo-si-077 \\
\hline 39 & Karnataka & Mandya & Z.A.R.S., Mandya & Jaya & Neck blast & $12^{\circ} 31^{\prime} \mathrm{N}, 76^{\circ} 54^{\prime} \mathrm{E} ; 113 \mathrm{~m}$ above sea level & Mo-si-080 \\
\hline 40 & Karnataka & Mandya & Malavalli & IR64 & Leaf blast & $12^{\circ} 22^{\prime} \mathrm{N}, 77^{\circ} 4^{\prime} \mathrm{E} ; 610 \mathrm{~m}$ above sea level & Mo-si-086 \\
\hline 43 & Karnataka & Mandya & Unknown & HR-12 & Leaf blast & $12^{\circ} 31^{\prime} \mathrm{N}, 76^{\circ} 54^{\prime} \mathrm{E} ; 113 \mathrm{~m}$ above sea level & Mo-si-082 \\
\hline 44 & Karnataka & Mandya & Unknown & AVT-IM T7 & Neck blast & $12^{\circ} 31^{\prime} \mathrm{N}, 76^{\circ} 54^{\prime} \mathrm{E} ; 113 \mathrm{~m}$ above sea level & Mo-si-084 \\
\hline 45 & Karnataka & Mandya & Z.A.R.S., Mandya & BPT5204 & Leaf blast & $12^{\circ} 31^{\prime} \mathrm{N}, 76^{\circ} 54^{\prime} \mathrm{E} ; 113 \mathrm{~m}$ above sea level & Mo-si-212 \\
\hline 46 & Karnataka & Raichur & Sirvar & Sona & Leaf blast & $16^{\circ} 10^{\prime} \mathrm{N}, 77^{\circ} 1^{\prime} \mathrm{E} ; 380 \mathrm{~m}$ above sea level & Mo-si-027 \\
\hline 47 & Karnataka & Raichur & Kavithal & Sona & Leaf blast & $16^{\circ} 10^{\prime} \mathrm{N}, 76^{\circ} 1^{\prime} \mathrm{E} ; 380 \mathrm{~m}$ above sea level & Mo-si-030 \\
\hline 48 & Karnataka & Raichur & Kalmala & Sona & Leaf blast & $16^{\circ} 10^{\prime} \mathrm{N}, 77^{\circ} 1^{\prime} \mathrm{E} ; 380 \mathrm{~m}$ above sea level & Mo-si-033 \\
\hline 49 & Karnataka & Raichur & Kelgaala Kamp & Sona & Leaf blast & $16^{\circ} 10^{\prime} \mathrm{N}, 77^{\circ} 1^{\prime} \mathrm{E} ; 380 \mathrm{~m}$ above sea level & Mo-si-032 \\
\hline 50 & Karnataka & Raichur & Yaraagera & Sona & Leaf blast & $16^{\circ} 10^{\prime} \mathrm{N}, 77^{\circ} 1^{\prime} \mathrm{E} ; 380 \mathrm{~m}$ above sea level & Mo-si-028 \\
\hline 51 & Karnataka & Raichur & Sindanoor & Sona & Leaf blast & $16^{\circ} 10^{\prime} \mathrm{N}, 77^{\circ} 1^{\prime} \mathrm{E} ; 380 \mathrm{~m}$ above sea level & Mo-si-029 \\
\hline 52 & Tamil Nadu & Erode & Bhavanisagar & ADT-29 & Leaf blast & $11^{\circ} 28^{\prime} \mathrm{N}, 77^{\circ} 7^{\prime} \mathrm{E} ; 329 \mathrm{~m}$ above sea level & Mo-si-087 \\
\hline 53 & Tamil Nadu & Erode & Bhavanisagar & Deluxe & Leaf blast & $11^{\circ} 28^{\prime} \mathrm{N}, 77^{\circ} 7^{\prime} \mathrm{E} ; 329 \mathrm{~m}$ above sea level & Mo-si-88 \\
\hline 54 & Tamil Nadu & Coimbatore & Gudalore & NSN & Leaf blast & $11^{\circ} 30^{\prime} \mathrm{N}, 76^{\circ} 30^{\prime} \mathrm{E} ; 1071 \mathrm{~m}$ above sea level & Mo-si-92 \\
\hline 55 & Tamil Nadu & Coimbatore & Gudalore & Bharti & Leaf blast & $11^{\circ} 30^{\prime} \mathrm{N}, 76^{\circ} 30^{\prime} \mathrm{E} ; 1071 \mathrm{~m}$ above sea level & Mo-si-89 \\
\hline 56 & Tamil Nadu & Coimbatore & Near Gudloor & Gandhakasala & Leaf blast & $11^{\circ} 30^{\prime} \mathrm{N}, 76^{\circ} 30^{\prime} \mathrm{E} ; 1071 \mathrm{~m}$ above sea level & Mo-si-93 \\
\hline 57 & Tamil Nadu & Coimbatore & Near Gudloor & Gandhakasala & Neck blast & $11^{\circ} 30^{\prime} \mathrm{N}, 76^{\circ} 30^{\prime} \mathrm{E} ; 1071 \mathrm{~m}$ above sea level & Mo-si-94 \\
\hline 58 & Tamil Nadu & Coimbatore & Gudalore & Bharti & Panical blast & $11^{\circ} 30^{\prime} \mathrm{N}, 76^{\circ} 30^{\prime} \mathrm{E} ; 1071 \mathrm{~m}$ above sea level & Mo-si-91 \\
\hline 59 & Tamil Nadu & Coimbatore & Gudalore & Bharti & Neck blast & $11^{\circ} 30^{\prime} \mathrm{N}, 76^{\circ} 30^{\prime} \mathrm{E} ; 1071 \mathrm{~m}$ above sea level & Mo-si-90 \\
\hline 60 & Tamil Nadu & Coimbatore & Gudalore & ADT-29 & Leaf blast & $11^{\circ} 30^{\prime} \mathrm{N}, 76^{\circ} 30^{\prime} \mathrm{E} ; 1071 \mathrm{~m}$ above sea level & Mo-si-87 \\
\hline 61 & Karnataka & Udupi & Kavadigrama & IET & Leaf blast & $13^{\circ} 19^{\prime} \mathrm{N}, 74^{\circ} 44^{\prime} \mathrm{E} ; 215 \mathrm{~m}$ above sea level & Mo-si-55 \\
\hline 62 & Karnataka & Udupi & Brahavar & Purple Putta & Leaf blast & $13^{\circ} 19^{\prime} \mathrm{N}, 74^{\circ} 44^{\prime} \mathrm{E} ; 215 \mathrm{~m}$ above sea level & Mo-si-121 \\
\hline 63 & Karnataka & Udupi & Brahavar & GMS-23-121 & Leaf blast & $13^{\circ} 19^{\prime} \mathrm{N}, 74^{\circ} 44^{\prime} \mathrm{E} ; 215 \mathrm{~m}$ above sea level & Mo-si-122 \\
\hline 64 & Karnataka & Udupi & Brahavar & Mo 4117 & Leaf blast & $13^{\circ} 19^{\prime} \mathrm{N}, 74^{\circ} 44^{\prime} \mathrm{E} ; 215 \mathrm{~m}$ above sea level & Mo-si-123 \\
\hline 65 & Karnataka & Uttara Kannada & ARS Sirsi & Unknown & Leaf blast & $14^{\circ} 20^{\prime} \mathrm{N}, 74^{\circ} 26^{\prime} \mathrm{E} ; 48 \mathrm{~m}$ above sea level & Mo-si-036 \\
\hline 66 & Karnataka & Uttara Kannada & Haliyal & Jaya & Leaf blast & $14^{\circ} 20^{\prime} \mathrm{N}, 74^{\circ} 26^{\prime} \mathrm{E} ; 48 \mathrm{~m}$ above sea level & Mo-si-034 \\
\hline 67 & Karnataka & Uttara Kannada & Kumata & Rasi & Neck blast & $14^{\circ} 20^{\prime} \mathrm{N}, 74^{\circ} 26^{\prime} \mathrm{E} ; 48 \mathrm{~m}$ above sea level & Mo-si-060 \\
\hline 68 & Karnataka & Koppal & Unknown & IET & Leaf blast & $15^{\circ} 25^{\prime} \mathrm{N}, 76^{\circ} 31^{\prime} \mathrm{E} ; 406 \mathrm{~m}$ above sea level & Mo-si-004 \\
\hline
\end{tabular}




\begin{tabular}{|c|c|c|c|c|c|c|c|}
\hline 69 & Karnataka & Koppal & Karatagi & BPT Rabi & Leaf blast & $15^{\circ} 25^{\prime} \mathrm{N}, 76^{\circ} 31^{\prime} \mathrm{E} ; 406 \mathrm{~m}$ above sea level & Mo-si-003 \\
\hline 70 & Karnataka & Koppal & Unknown & G-B-30 & Leaf blast & $15^{\circ} 25^{\prime} \mathrm{N}, 76^{\circ} 31^{\prime} \mathrm{E} ; 406 \mathrm{~m}$ above sea level & Mo-si-007a \\
\hline 71 & Karnataka & Koppal & Gangavathi & BPT5204 & Leaf blast & $15^{\circ} 25^{\prime} \mathrm{N}, 76^{\circ} 31^{\prime} \mathrm{E} ; 406 \mathrm{~m}$ above sea level & Mo-si-007 \\
\hline 72 & Karnataka & Koppal & Gangavathi & HR-12 & Leaf blast & $15^{\circ} 25^{\prime} \mathrm{N}, 76^{\circ} 31^{\prime} \mathrm{E} ; 406 \mathrm{~m}$ above sea level & Mo-si-005 \\
\hline 73 & Karnataka & Koppal & Gangavathi & BPT5204 & Neck blast & $15^{\circ} 25^{\prime} \mathrm{N}, 76^{\circ} 31^{\prime} \mathrm{E} ; 406 \mathrm{~m}$ above sea level & Mo-si-006 \\
\hline 74 & Karnataka & Koppal & A.R.S., Gangavathi & DHB-19 & Leaf blast & $15^{\circ} 25^{\prime} \mathrm{N}, 76^{\circ} 31^{\prime} \mathrm{E} ; 406 \mathrm{~m}$ above sea level & Mo-si-124 \\
\hline 75 & Karnataka & Koppal & A.R.S., Gangavathi & DHA & Leaf blast & $15^{\circ} 25^{\prime} \mathrm{N}, 76^{\circ} 31^{\prime} \mathrm{E} ; 406 \mathrm{~m}$ above sea level & Mo-si-125 \\
\hline 76 & Karnataka & Koppal & Sirguppa & Sona & Leaf blast & $15^{\circ} 25^{\prime} \mathrm{N}, 76^{\circ} 31^{\prime} \mathrm{E} ; 406 \mathrm{~m}$ above sea level & Mo-si-214a \\
\hline 77 & Karnataka & Koppal & Sirguppa & Sona & Neck blast & $15^{\circ} 25^{\prime} \mathrm{N}, 76^{\circ} 31^{\prime} \mathrm{E} ; 406 \mathrm{~m}$ above sea level & Mo-si-214b \\
\hline 79 & Karnataka & Koppal & Unknown & A.B.Godi & Leaf blast & $15^{\circ} 25^{\prime} \mathrm{N}, 76^{\circ} 31^{\prime} \mathrm{E} ; 406 \mathrm{~m}$ above sea level & Mo-ni-216 \\
\hline 80 & Karnataka & Chikkamangalore & Mudegeri & Gamsali & Leaf blast & $13^{\circ} 32^{\prime} \mathrm{N}, 75^{\circ} 77^{\prime} \mathrm{E} ; 1926 \mathrm{~m}$ above sea level & Mo-si-15a \\
\hline 81 & Karnataka & Chikkamangalore & Mudegeri & Gamsali & Neck blast & $13^{\circ} 32^{\prime} \mathrm{N}, 75^{\circ} 77^{\prime} \mathrm{E} ; 1926 \mathrm{~m}$ above sea level & Mo-si-15b \\
\hline 82 & Karnataka & Chikkamangalore & Mudegeri & Gamsali & Seeds & $13^{\circ} 32^{\prime} \mathrm{N}, 75^{\circ} 77^{\prime} \mathrm{E} ; 1926 \mathrm{~m}$ above sea level & Mo-si-15c \\
\hline 83 & Karnataka & Chikkamangalore & Anegal & Chandibatta & Leaf blast & $13^{\circ} 32^{\prime} \mathrm{N}, 75^{\circ} 77^{\prime} \mathrm{E} ; 1926 \mathrm{~m}$ above sea level & Mo-si-11 \\
\hline 84 & Karnataka & Chikkamangalore & Somvarpete & Holesalu chippiga & Leaf blast & $13^{\circ} 32^{\prime} \mathrm{N}, 75^{\circ} 77^{\prime} \mathrm{E} ; 1926 \mathrm{~m}$ above sea level & Mo-si-13 \\
\hline 85 & Karnataka & Chikkamangalore & Unknown & Doddibatta & Leaf blast & $13^{\circ} 32^{\prime} \mathrm{N}, 75^{\circ} 77^{\prime} \mathrm{E} ; 1926 \mathrm{~m}$ above sea level & Mo-si-12 \\
\hline 86 & Karnataka & Shimogga & Talaguppa & Intan & Leaf blast & $13^{\circ} 56^{\prime} \mathrm{N}, 75^{\circ} 34^{\prime} \mathrm{E} ; 569 \mathrm{~m}$ above sea level & Mo-si-23 \\
\hline 87 & Karnataka & Tumkur & Kunigal & Rasi & Leaf blast & $13^{\circ} 1^{\prime} \mathrm{N}, 75^{\circ} 34^{\prime} \mathrm{E} ; 773 \mathrm{~m}$ above sea level & Mo-si-78 \\
\hline 89 & Karnataka & Hassan & Sakleshpura & Intan & Leaf blast & $12^{\circ} 58^{\prime} \mathrm{N}, 75^{\circ} 46^{\prime} \mathrm{E} ; 949 \mathrm{~m}$ above sea level & Mo-si-98a \\
\hline 90 & Kerala & Kasaragod & Mavangal & Athira & Leaf blast & $10^{\circ} 17^{\prime} \mathrm{N}, 76^{\circ} 32^{\prime} \mathrm{E} ; 80 \mathrm{~m}$ above sea level & Mo-si-64 \\
\hline 91 & $\begin{array}{l}\text { Andhra } \\
\text { Pradesh }\end{array}$ & Vizianagaram & Vizianagaram & MTU1010 & Leaf blast & $18^{\circ} 7^{\prime} \mathrm{N}, 83^{\circ} 25^{\prime} \mathrm{E} ; 66 \mathrm{~m}$ above sea level & Mo-si-63 \\
\hline 92 & $\begin{array}{c}\text { Uttar } \\
\text { Pradesh }\end{array}$ & Meerut & Unknown & Basmati rice & Leaf blast & $28^{\circ} 59^{\prime} \mathrm{N}, 77^{\circ} 42^{\prime} \mathrm{E} ; 224 \mathrm{~m}$ above sea level & Mo-si-66 \\
\hline 93 & Kerala & Kasaragod & Narlan & Aravadha pille & Leaf blast & $12^{\circ} 30^{\prime} \mathrm{N}, 75^{\circ} 0^{\prime} \mathrm{E} ; 19 \mathrm{~m}$ above sea level & Mo-si-74 \\
\hline 94 & Karnataka & Ankola & Haladipura & Rasi & Leaf blast & $14^{\circ} 66^{\prime} \mathrm{N}, 74^{\circ} 3^{\prime} \mathrm{E} ; 16 \mathrm{~m}$ above sea level & Mo-si-60 \\
\hline 95 & Karnataka & Ankola & Apsarakonda & Jyoti & Leaf blast & $14^{\circ} 66^{\prime} \mathrm{N}, 74^{\circ} 3^{\prime} \mathrm{E} ; 16 \mathrm{~m}$ above sea level & Mo-si-61 \\
\hline 96 & Tamil Nadu & Unknown & Unknown & Gandhakasala & Leaf blast & $11^{\circ} 30^{\prime} \mathrm{N}, 76^{\circ} 30^{\prime} \mathrm{E} ; 1071 \mathrm{~m}$ above sea level & Mo-si-93a \\
\hline 97 & Karnataka & Dharwad & Mugad & BPT & Leaf blast & $15^{\circ} 27^{\prime} \mathrm{N}, 74^{\circ} 55^{\prime} \mathrm{E} ; 687 \mathrm{~m}$ above sea level & Mo-si-217 \\
\hline
\end{tabular}

\section{Determination of mating type and fertility status of unknown isolates:}

The mating types of Mo-si-88 and Mo-si-15a (unknown mating types isolates) were determined by pairing each isolates three times with seven hermaphroditic testers Mo-si-007, Mo-si-215, Mo-si-15c, Mo-si-53, Mo-si-98a, Mosi-076a and Mo-si-084.

Crosses were made by pairing in Petri dishes (TARSONS Petri dish with triple vent Radiation Sterile Manufactured by: Tarsons Products Pvt. Ltd.) containing Rice Straw Agar supplemented with streptomycin by pairing actively growing mycelia of Magnaporthe oryzae isolates and cultures were observed under phase contrast microscope (Nikon Digital Sight ECLIPSE E600 - Olympus) Nikon's NIS-Elements microscope imaging software used. All Observations, measurements and Microphotographs were taken and noted under this study. Sporulation process was observed in 4-5 microscopic fields. Sporulation rate was divided as Nil, Poor, Fair, Good and Excellent. The isolates were monitored regularly for the development of sexual structures for 1-3 months. Itoi et al., 1983 described the way how we can identify the fertility status of unknown isolates (Fig.1).

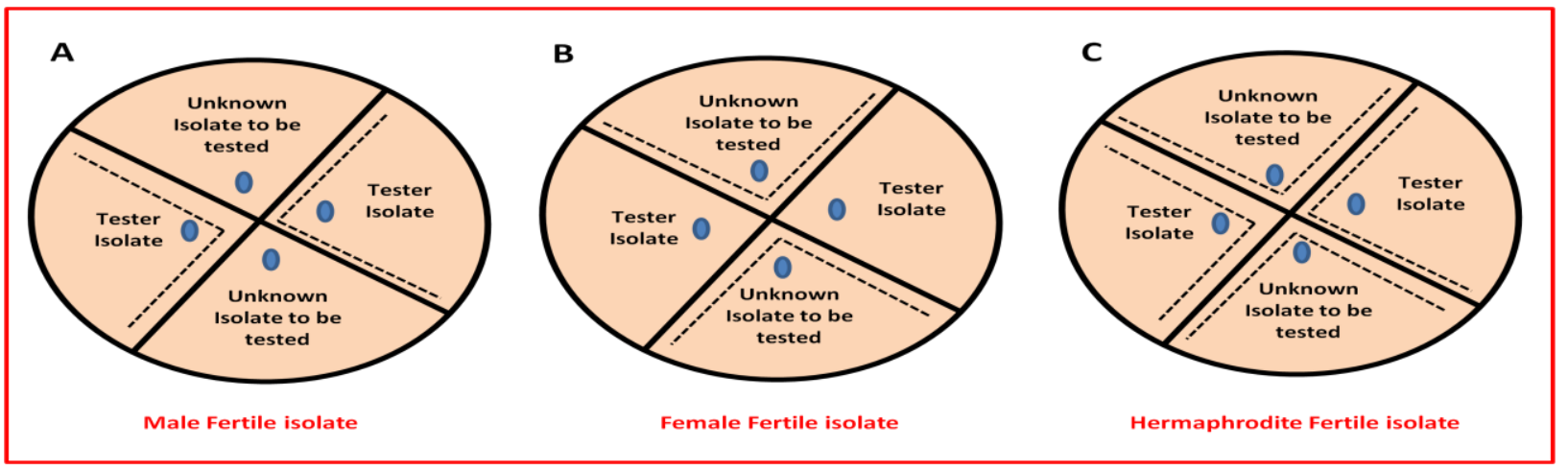

Fig. (1): Determination of mating type and fertility status of unknown isolates: A. Male fertile isolates induce perithecia on the tester isolate side. B. When perithecia formed on the side of unknown isolates, cultures considered as female fertile. C. Hermaphrodite isolates produce perithecia on both sides of the merger line (interface) between the unknown isolate and the tester isolate. 


\section{Results:}

A total of ninety seven isolates of Magnaporthe oryzae collected from different locations of south India were evaluated to understand the mating type distribution and fertility of isolates by using MAT locus specific primers (Table 2). MAT1-1 (Male fertile) mating type generated the amplicon of 809 bp (Fig.2) where as MAT1-2 (Female fertile) yielded amplicon size of 940bp (Fig.3).

Table 2: Mating types distribution of Magnaporthe oryzae based on mating type alleles of MAT locus

\begin{tabular}{|c|c|c|c|c|c|c|c|c|}
\hline Sr.No. & Isolate ID & Place of collection & Host variety & MAT1-1 & MAT1-2 & $\begin{array}{c}\text { Male } \\
\text { Fertile }\end{array}$ & $\begin{array}{l}\text { Female } \\
\text { Fertile }\end{array}$ & Hermaphrodite \\
\hline 1 & Mo-si-105 & A.R.S., Mugad & HR-12 & + & - & $\checkmark$ & & \\
\hline 2 & Mo-si-106 & A.R.S., Mugad & Intan L.B & + & - & $\checkmark$ & & \\
\hline 3 & $\begin{array}{l}\text { Mo-si-107 } \\
\end{array}$ & A.R.S., Mugad & Honasu & - & + & & $\checkmark$ & \\
\hline 4 & Mo-si-108 & A.R.S., Mugad & Nyareminda & + & 1 & 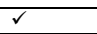 & & \\
\hline 5 & Mo-si-109 & A.R.S., Mugad & Kiravanna & + & - & $\checkmark$ & & \\
\hline 6 & Mo-si-110 & A.R.S., Mugad & Kari Esadi & + & - & 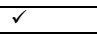 & & \\
\hline 7 & Mo-si-111 & A.R.S., Mugad & Pramod & + & - & 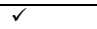 & & \\
\hline 8 & Mo-si-112 & A.R.S., Mugad & Jeerigesanna & + & - & $\checkmark$ & & \\
\hline 9 & Mo-si-113 & A.R.S., Mugad & Jaddu batta & + & - & $\checkmark$ & & \\
\hline 10 & Mo-si-114 & A.R.S., Mugad & Intan N.B & + & - & $\checkmark$ & & \\
\hline 11 & Mo-si-115 & A.R.S., Mugad & Jirga & + & - & $\checkmark$ & & \\
\hline 12 & $M o-s i-16 b$ & Mugad & Intan & + & - & $\checkmark$ & & \\
\hline 13 & $\begin{array}{ll}M o-s i-116 \\
\end{array}$ & A.R.S., Mugad & Ashoka 200F & + & - & $\checkmark$ & & \\
\hline 14 & $M o-s i-200$ & A.R.S., Mugad & Chippiga & + & - & $\checkmark$ & & \\
\hline 15 & $\begin{array}{l}\text { Mo-si-201 } \\
\end{array}$ & A.R.S., Mugad & Gum Kadle & + & - & $\checkmark$ & & \\
\hline 16 & Mo-si-202 & Mugad & Unknown N.B & + & - & $\checkmark$ & & \\
\hline 17 & Mo-si-203 & A.R.S., Mugad & Kempu Dodda & + & - & $\checkmark$ & & \\
\hline 18 & Mo-si-204 & A.R.S., Mugad & Billi Hege & + & - & 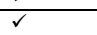 & & \\
\hline 19 & Mo-si-205 & A.R.S., Mugad & Jondole Jeerge & + & - & $\checkmark$ & & \\
\hline 20 & $\begin{array}{l}M o-s i-206 \\
\end{array}$ & A.R.S., Mugad & Bangar sanna & - & + & & $\checkmark$ & \\
\hline 21 & Mo-si-207 & A.R.S., Mugad & Ambemohr-1 & - & + & & $\checkmark \checkmark$ & \\
\hline 22 & $\begin{array}{ll}\text { Mo-si-208 } \\
\end{array}$ & A.R.S., Mugad & Gum KadleN.B & + & - & $\checkmark$ & & \\
\hline 23 & Mo-si-102 & A.R.S., Mugad & BPT5204 & + & - & $\checkmark$ & & \\
\hline 24 & Mo-si-209 & A.R.S., Mugad & Jeerige sanna- 2 & - & + & & $\checkmark$ & \\
\hline 25 & $M o-s i-210$ & A.R.S., Mugad & BPT5204 & + & $\begin{array}{l}\mathrm{T} \\
-\end{array}$ & $\checkmark$ & & \\
\hline 26 & Mo-si-99 & A.R.S., Mugad & DHB1 & - & + & & $\checkmark$ & \\
\hline 27 & $\begin{array}{l}\text { Mo-si-100 } \\
\end{array}$ & A.R.S., Mugad & DHB4 & - & + & & $\checkmark$ & \\
\hline 28 & $M o-s i-211$ & Unknown2012 & Unknown & - & + & & 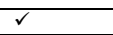 & \\
\hline 29 & Mo-si-048 & Ponnampet & Asha & + & - & $\checkmark$ & & \\
\hline 30 & Mo-si-117 & Ponnampet & DHB-30 & - & + & & $\checkmark$ & \\
\hline 31 & Mo-si-118 & Ponnampet & DHB-25 & - & + & & 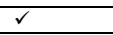 & \\
\hline 32 & Mo-si-119 & Ponnampet & Unknown & - & $+\frac{t}{+}$ & & $\checkmark$ & \\
\hline 33 & $M o-s i-120$ & Ponnampet & HR-12 & - & + & & $\checkmark$ & \\
\hline 34 & Mo-si-050 & Ponnampet & Mysore & + & - & $\checkmark$ & & \\
\hline 35 & Mo-si-081 & Z.A.R.S., Mandya & NSN & + & - & $\checkmark$ & & \\
\hline 36 & Mo-si-083 & Unknown & KMP N.B & - & + & & $\checkmark$ & \\
\hline 37 & Mo-si-079 & Z.A.R.S., Mandya & Jaya & - & + & & $\checkmark$ & \\
\hline 38 & Mo-si-077 & Unknown & Unknown NB & - & + & & 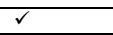 & \\
\hline 39 & Mo-si-080 & Z.A.R.S., Mandya & Jaya N.B & - & + & & $\checkmark$ & \\
\hline 40 & Mo-si-086 & Malavalli & IR64 & - & + & & $\checkmark r$ & \\
\hline 41 & Mo-si-076a & Yamanahalli & MTU1001 & + & + & & & 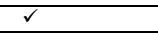 \\
\hline$\frac{41}{42}$ & $M o$-si-076b & Maddur & MTU1001 & - & + & & $\bar{d}$ & \\
\hline 43 & $M o-s i-082$ & Unknown & HR-12 & - & + & & $\checkmark$ & \\
\hline 44 & $\begin{array}{ll}\text { Mo-si-084 } \\
\end{array}$ & Unknown & AVI-IM T7N.B & + & + & & & $\checkmark$ \\
\hline 45 & $M o-s i-212$ & Z.A.R.S., Mandya & BPT5204 & - & + & & $\checkmark$ & \\
\hline 46 & Mo-si-027 & Sirvar & Sona & + & - & $\checkmark$ & & \\
\hline 47 & Mo-si-030 & Kavithal & Sona & - & + & & $\checkmark$ & \\
\hline 48 & $M o-s i-033$ & Kalmala & Sona & + & - & $\checkmark$ & & \\
\hline 49 & $M o-s i-032$ & Kelgaala Kamp & Sona & + & - & $\checkmark$ & & \\
\hline 50 & Mo-si-028 & Yaraagera & Sona & + & - & & $\checkmark$ & \\
\hline 51 & $\begin{array}{l}\text { Mo-si-029 } \\
\end{array}$ & Sindanoor & Sona & - & + & & $\checkmark$ & \\
\hline 52 & Mo-si-087 & Bhavanisagar & ADT-29 & - & + & & $\checkmark$ & \\
\hline 53 & Mo-si-88 & Bhavanisagar & Deluxe & - & - & & & Unknown \\
\hline 54 & Mo-si-92 & Gudalore & NSN & + & - & $\checkmark$ & & \\
\hline 55 & Mo-si-89 & Gudalore & Bharti & + & - & 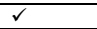 & & \\
\hline 56 & $M o-s i-93$ & Near Gudloor & Gandhakasala & + & - & $\checkmark$ & & \\
\hline 57 & Mo-si-94 & Near Gudloor & GandhakasalaN.B & + & - & $\checkmark$ & & \\
\hline 58 & Mo-si-9I & Gudalore & Bharti seeds & - & + & & $\checkmark$ & \\
\hline 59 & Mo-si-90 & Gudalore & Bharti N.B & - & + & & $\checkmark$ & \\
\hline 60 & Mo-si-87 & Gudalore & ADT-29 & + & - & $\checkmark$ & & \\
\hline 61 & $M o-s i-55$ & Kavadigrama & IET & - & + & & $\checkmark$ & \\
\hline 62 & Mo-si-121 & Brahavar & Purple Putta & - & + & & $\checkmark$ & \\
\hline 63 & $M o-s i-122$ & Brahavar & GMS-23-121 & + & - & 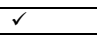 & & \\
\hline 64 & $M o-s i-123$ & Brahavar & Mo 4117 & + & - & $\checkmark$ & & \\
\hline 65 & $\begin{array}{ll}\text { Mo-si-036 } \\
\end{array}$ & ARS Sirsi & Unknown & - & + & & $\checkmark$ & \\
\hline 66 & Mo-si-034 & Haliyal & Jaya & + & - & $\checkmark$ & & \\
\hline 67 & Mo-si-060 & Kumata & Rasi N.B & + & - & $\checkmark$ & & \\
\hline 68 & Mo-si-004 & Unknown & IET & + & - & $\checkmark$ & & \\
\hline 69 & Mo-si-003 & Karatagi & BPT Rabi & - & + & & $\checkmark r$ & \\
\hline 70 & Mo-si-007a & Unknown & GB-30 & + & - & $\checkmark r$ & & \\
\hline 71 & Mo-si-007 & Gangavathi & $\begin{array}{l}\text { BPT5204 } \\
\end{array}$ & + & + & & & $\checkmark$ \\
\hline 72 & Mo-si-005 & Gangavathi & HR-12 & - & + & & $\checkmark$ & \\
\hline 73 & Mo-si-006 & Gangavathi & BPT5204 N.B & - & + & & $\checkmark$ & \\
\hline 74 & Mo-si-124 & A.R.S., Gangavathi & DHB-19 & & + & & $\checkmark$ & \\
\hline
\end{tabular}




\begin{tabular}{|c|c|c|c|c|c|c|c|c|}
\hline 75 & Mo-si-125 & A.R.S., Gangavathi & DHA & - & + & & $\checkmark$ & \\
\hline 76 & $M o$-si-214a & Sirguppa & $\begin{array}{l}\text { Sona L.B } \\
\end{array}$ & - & + & & $\checkmark$ & \\
\hline 77 & $M o-s i-214 b$ & $\begin{array}{l}\text { Sirguppa } \\
\end{array}$ & Sona N.B & - & + & & $\checkmark$ & \\
\hline 78 & Mo-si-215 & Unknown & GB-30 N.B & + & + & & & $\checkmark$ \\
\hline 79 & Mo-ni-216 & Unknown & A.B.Godi & + & - & $\checkmark$ & & \\
\hline 80 & $M o-s i-15 a$ & Mudegeri & Gamsali L.B & - & - & & & Unknown \\
\hline 81 & $M o-s i-15 b$ & Mudegeri & Gamsali N.B & - & + & & $\checkmark$ & \\
\hline 82 & $M o-s i-15 c$ & Mudegeri & Gamsali seeds & + & + & & & $\checkmark$ \\
\hline 83 & Mo-si-11 & Unknown & Chandibatta & + & - & $\checkmark$ & & \\
\hline 84 & Mo-si-13 & Somvarpete & Holesalu chippiga & + & - & $\checkmark$ & & \\
\hline 86 & Mo-si-23 & Talaguppa & Intan & - & + & & $\checkmark$ & \\
\hline 87 & Mo-si-78 & Kunigal & Rasi & - & + & & $\checkmark$ & \\
\hline 88 & \begin{tabular}{|l}
$M o-s i-53$ \\
\end{tabular} & Bheemrayanagudi & Sujatha & + & + & & & $\checkmark$ \\
\hline 89 & Mo-si-98a & Sakleshpura & Intan & + & + & & & $\checkmark$ \\
\hline 90 & Mo-si-64 & Mavangal & Athira & - & + & & $\checkmark$ & \\
\hline 91 & Mo-si-63 & Vizianagaram & MTU1010 & - & + & & $\checkmark$ & \\
\hline 92 & Mo-si-66 & Unknown & Basmati rice & - & + & & $\checkmark$ & \\
\hline 93 & Mo-si-74 & Narlan & Aravadha pille & + & - & $\checkmark$ & & \\
\hline 94 & Mo-si-60 & Haladipura & Rasi & + & - & $\checkmark$ & & \\
\hline 95 & Mo-si-61 & Apsarakonda & Jyoti & - & + & & $\checkmark$ & \\
\hline 97 & Mo-si-217 & Mugad & BPT & + & - & $\checkmark$ & & \\
\hline
\end{tabular}

Among 97 isolates 46 isolates were MAT1-1 mating type accounting to 47.42 per cent frequency. 42 isolates were positive for MAT1-2 mating type with 43.29 per cent frequency. About seven isolates were hermaphrodite type with 7.21 per cent frequency and two isolates showed unknown mating type, which showed negative amplification for both MAT1-1 and MAT1-2 gene specific primers (Fig.4).

The highest frequencies of isolates that could be typed for MAT1-1 were detected in Dharward around 22 isolates with 75.86 per cent frequency (Fig.5), while MAT1-2 type recorded 24.13 per cent frequency in 7 isolates. MAT1-2 (Female fertile) was predominant in Kodagu isolates with 66.66 per cent of samples were female fertile where as MAT1-1 accounted 33.33 per cent frequency. No hermaphrodite and unknown mating types were observed in these two locations.

MAT1-1, MAT1-2 and hermaphrodite isolates were traced in Mandya cultures collection with 72.72 per cent frequency for MAT1-2, 9 per cent for MAT1-1 type and two isolates Mo-si-076a Yamanahalli (MTU1001L.B) and Mo-si-084 M.A.R.S. Mandya (Unknown, N.B) showed hermaphrodite isolates with 18.18 per cent frequency.

Both the mating types were observed in isolates collected from Raichur district which represents irrigated rice ecology and Uttara kannada district which is rainfed ecology encompassing MAT1-1 mating type with 60 per cent frequency and MAT1-2 mating type with 40\%. Isolates collected from Koppal district contained MAT1-1, MAT1-2 and hermaphrodite mating types with $25,58.33$ and 16.66 per cent frequency respectively. Two isolates from Gangavathi and unknown location sample showed hermaphrodite mating type Similarly Chikkamangalore isolates showed MAT1-1, MAT1-2, hermaphrodite and unknown mating types with 50, 16.66, 16.66 and 16.66 per cent frequency respectively. In this location two of the isolates showed no amplification for either of the two mating types.

Kerela isolates consisting of only two cultures which showed MAT1-1 and MAT1-2 type1:1 ratio. Tamil Nadu rice blast isolates results showed 40 per cent of samples presented as MAT1-2, 50 per cent frequency recorded for MAT1-1 and 10 per cent unknown mating types. No hermaphrodite type was observed in Tamil Nadu isolates.

Different locations isolates in south India from Shimogga, Tumkur, Kalaburgi, Hassan, Vizianagaram and Meerut, showed 66.66 per cent frequency for mating type MAT1-2, and 33.33 per cent for hermaphrodite mating type. Hermaphrodite isolates were noticed, Bhhemrayana Gudi (Sujatha variety) Mo-si-53 isolate and Sakleshpura (Intan Variety) Mo-si-98(a) isolate.

Cultures were checked for sporulation and all of them were highly sporulated cultures (Fig.6) which used in crosses experiment. Production of Perithecia were not seeing when the cross between isolates of the opposite was done. 

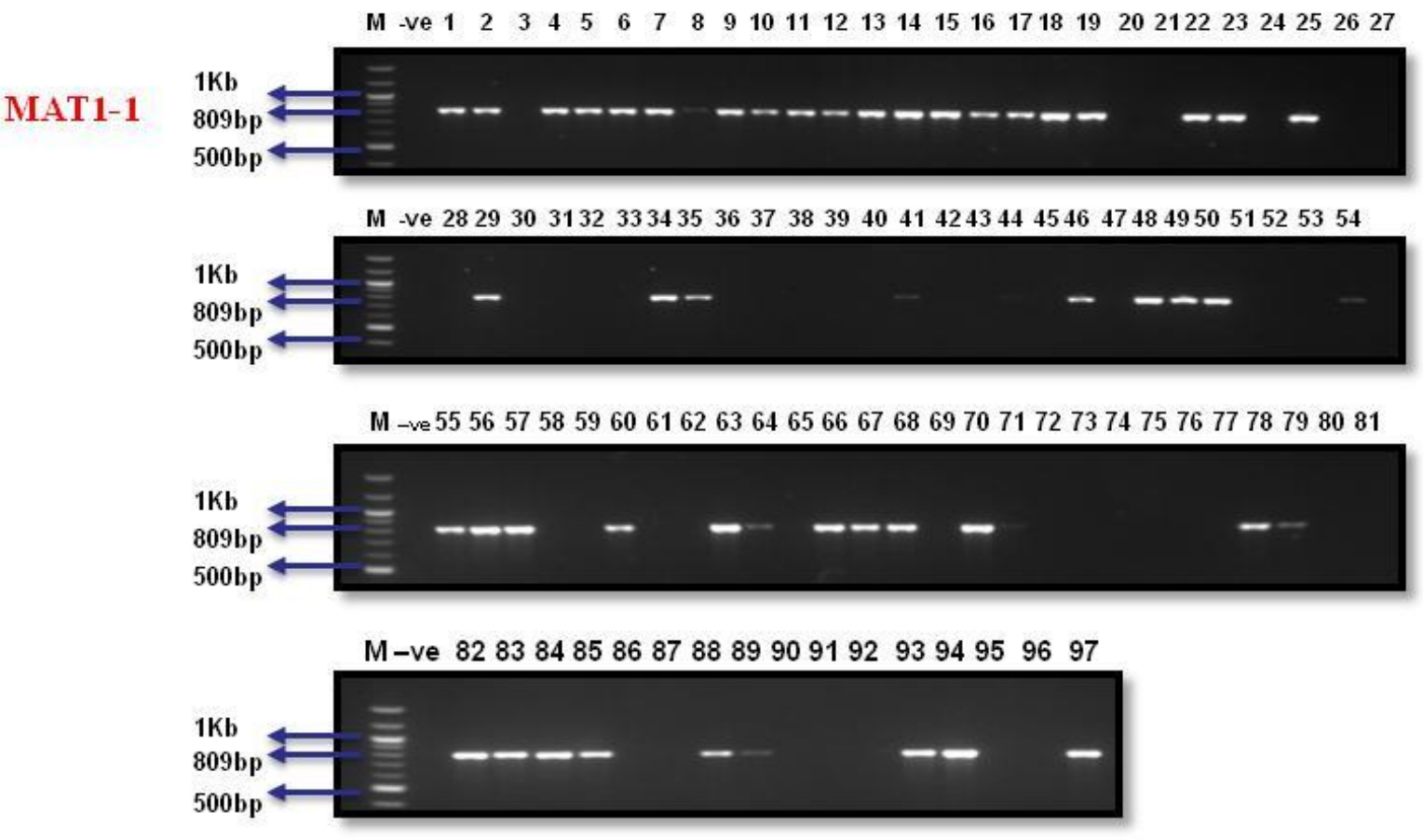

Fig. (2): Amplification of MAT1-1 mating types of $M$. oryzae by gene specific primers
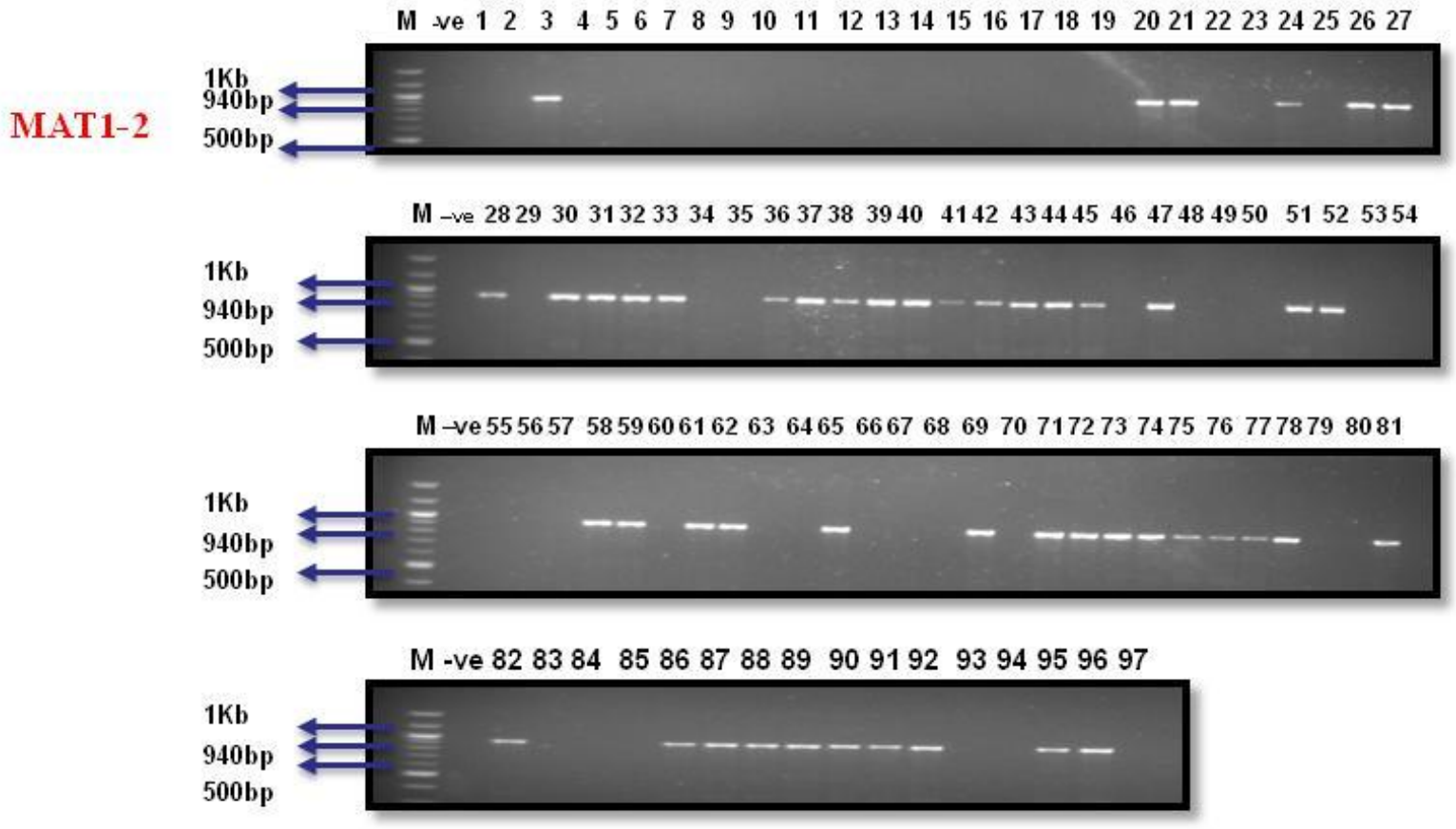

Fig. (3): Amplification of MAT1-2 mating types of M. oryzae by gene specific primers

(M- 100bp DNA ladder - -Ve Negative Control - 1-97 Magnaporthe Oryzae isolates) 


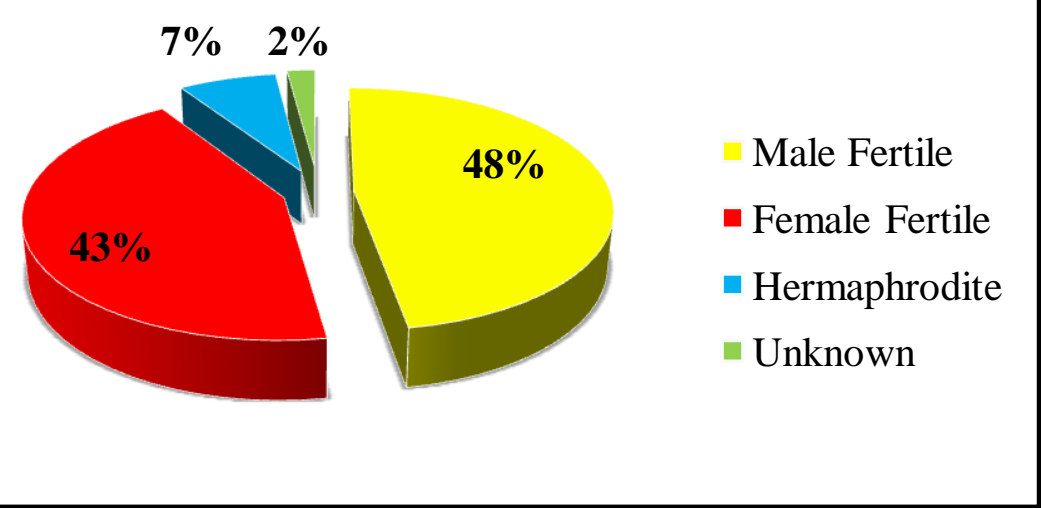

Fig. (4):- Mating types total frequencies in Magnaporthe oryzae isolates

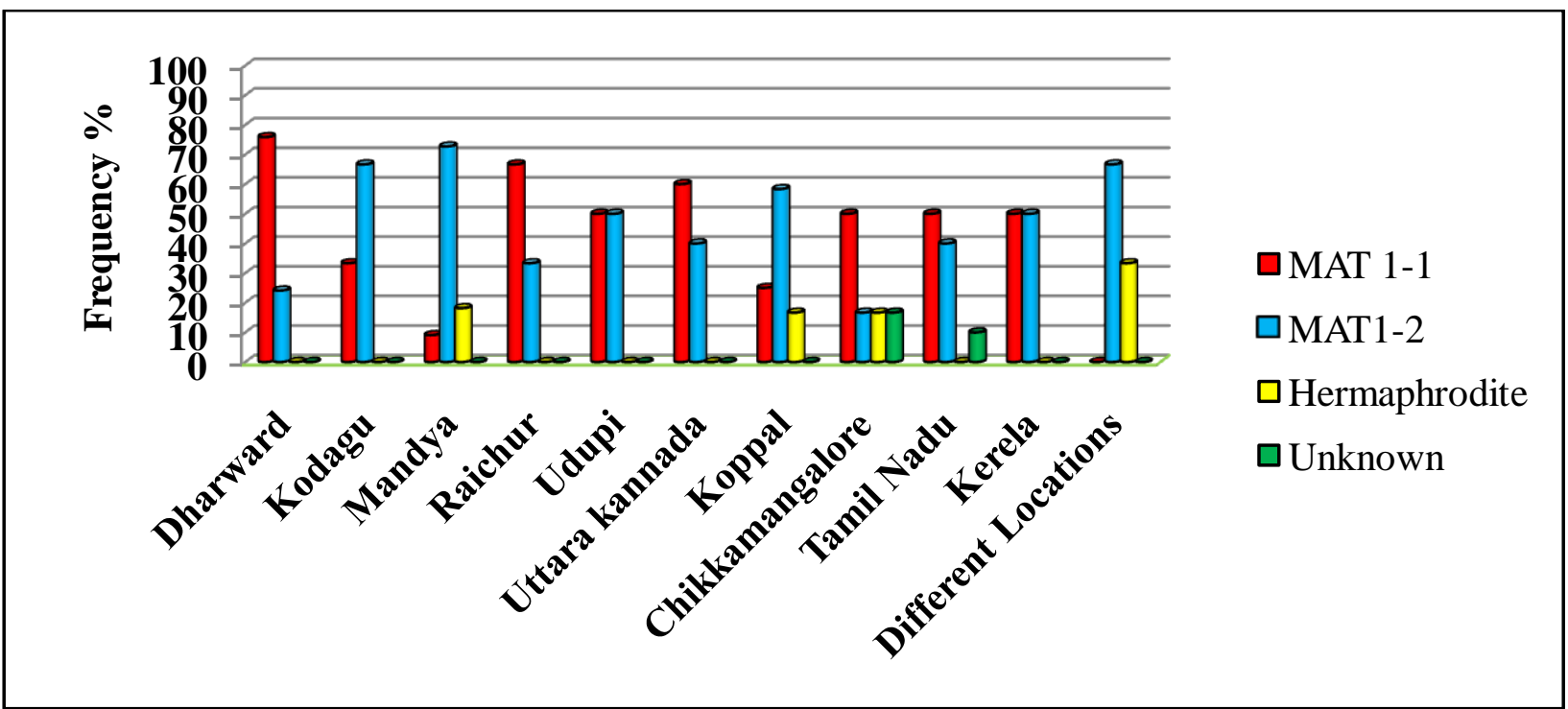

Fig.(5):- District /state wise distribution of mating types in Magnaporthe oryzae isolates

\section{Discussion:}

Magnaporthe is a hermaphroditic, heterothallic ascomycete (anamorph: Pyricularia grisea) pathogenic to a large number of gramineae species. Magnaporthe oryzae is known for its high capacity of asexual spore production and wide variation in the field. Both sexual and asexual stages are seen in the life cycles of ascomycetous fungi. In many fungi, including M. oryzae sexual cycle is controlled by mating type genes (Consola et al., 2005; Leslie and Klein, 1996 and Zeng et al., 2009). M. oryzae can only mate when two fertile opposite mating- types are present. Sexual propagation in M. oryzae is controlled by MAT (mating-type) locus, which is represented by two idiomorphs known as MAT1-1 (Male fertile) and MAT1-2 (Female fertile).

Until recently sexually fertile rice isolates were thought to be very rare and variations were attributed to parasexual recombination, mutations and clonal lineages. 
A

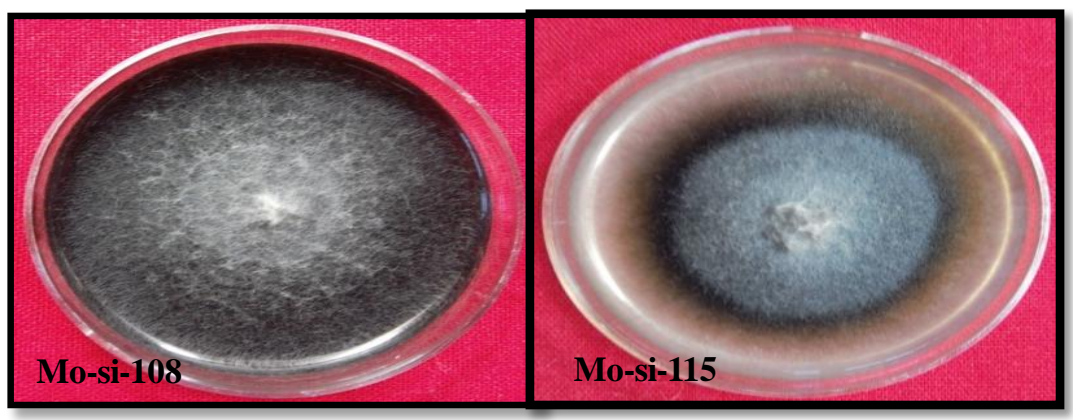

B

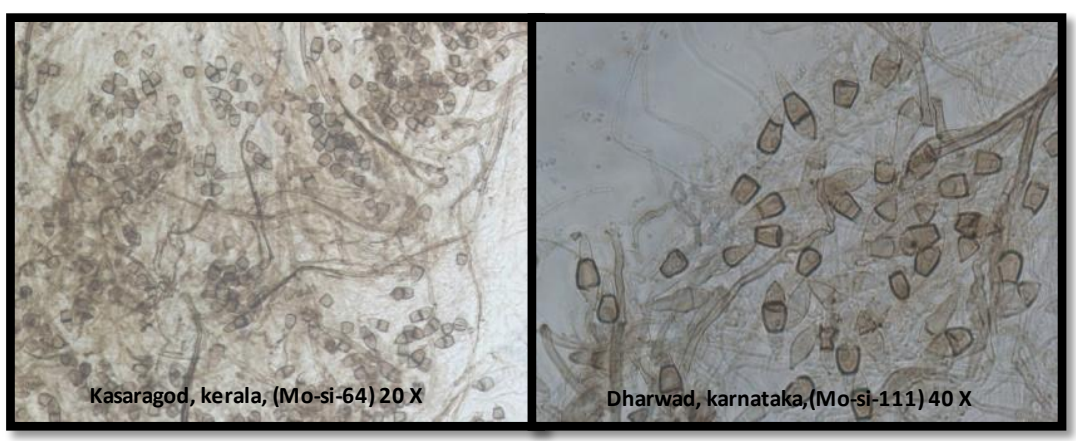

C

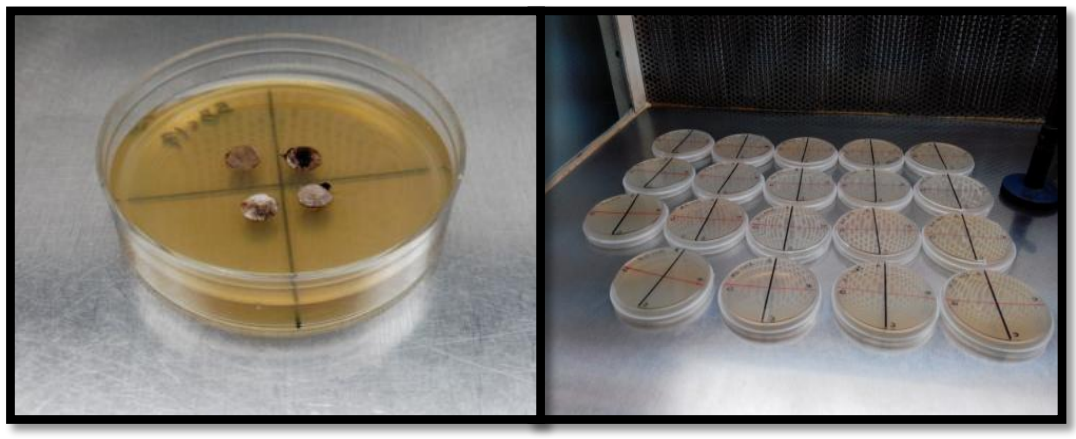

D

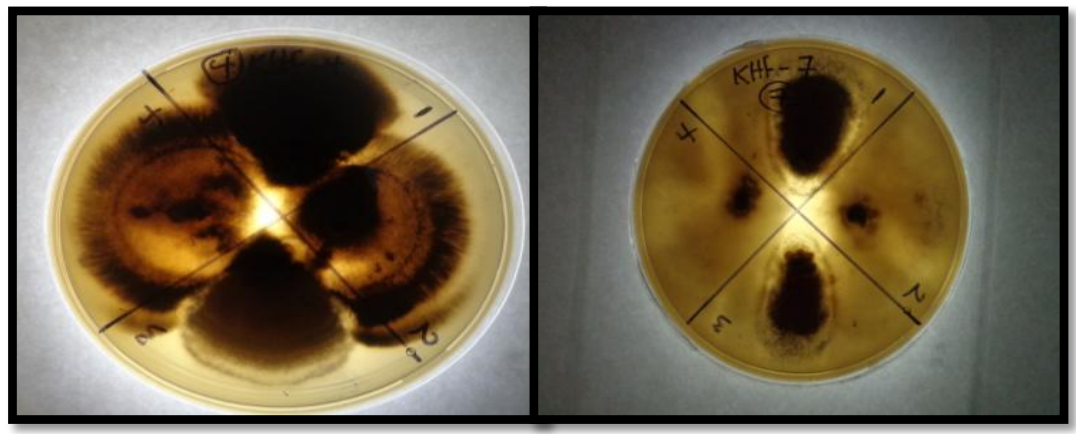

Fig. (6): Cultures, Sporulation and crosses between Magnaporthe Oryzae Isolates

A. Two cultures of Magnaporthe oryzae isolates on Rice Straw Agar. B. Pyriform conidia and highly sporulated Magnaporthe oryzae. C. Magnaporthe oryzae isolates pairing; Testers with unknown isolates using filter paper disk. D. Full growth of crossed cultures for mating type determination and fertility status of unknown isolates. 
Sexual reproduction can reshuffle genetic material via recombination, thereby bringing together new alleles, which may influence pathogenicity to various rice cultivars and could influence the efficacy of fungicides. Capacity of $M$. grisea isolates to produce perithecia (female fertility) is apparently controlled by genes at several loci, and these segregate independently of mating type and of pathogenicity on different hosts (Mekwatanakarn et al., 1999). In fertility surveys of rice pathogens results were generally consistent in that female sterility was the norm, fertile isolates were typically male-fertile only, and mating type ratios were skewed (Notteghem and Silué, 1992; Yaegashi and Nishihara, 1976). This rarity of female fertility was consistent with the reported abundance of transposable elements in M. grisea rice pathogens (Zeigler, 1998; Zeigler et al., 1994). In the late 1980s, hermaphroditic (male and female-fertile) rice isolates were found and subsequently used as tester strains against field isolates as well as in back-crossing programs to develop fertile rice isolates of both mating types (Mekwatanakarn et al., 1999). A study from Southern India reported no sexually fertile rice pathogens (Devulapalle and Suryanarayanan, 1995; Viji and Gnanamanickam, 1998).

However, in our present study among 97 isolates seven isolates showed the amplification for both MAT alleles indicating these isolates are male and female-fertile. Isolates Mo-si-076a, Mo-si-084, Mo-si-007, Mosi-215, Mo-si-15c, Mo-si-53, Mo-si-98a, are hermaphroditic and hence these can be used as tester strains to identify and clone new avirulence genes in several field isolates. Both male 75.86 per cent and female fertile 24.13 per cent isolates were recovered from a single field of A.R.S Mugad. Similarly in other surveyed locations both mating alleles were recorded. Samples collected from Kodagu, Mandya and Koppal location was dominated by female fertile isolates 58.33 per cent to 72.72 per cent.

Conventional approach to determine mating type in the pathogen population depends upon the appearance of mature perithecia in a cross between known tester and an unknown strain on culture media which is time consuming and requires high technical expertise. PCR amplification methods using MAT gene specific primers are a rapid method to explore the mating type population of M. oryzae (Priyadarisini et al., 1999; Notteghem and Silué, 1992: Hayashi et al., 1997, Zheng et al., 2008; Dong et al., 2005).

Comparison of PCR method and the standard strain GUY11 / KA3 mating type assays showed good consensus 95.1 per cent (Bao-Hua et al., 2004). In the present study same set of primers were used to amplify MAT alleles governing fertility in M. oryzae. The size of PCR product produced by MAT1-1 and MAT1-2 in this study was similar to the bands observed by earlier workers (Bau-Hua et al., 2004; Soma et al., 2014).

Analysis of mating type can provide an estimation of genetic diversity among $M$. oryzae populations from rice. Genetic diversity and mating-type studies suggested that $M$. oryzae exists as a recombinant population. However, detection of sexual form in natural field conditions and the pathogenicity of its progenies on rice still remain elusive despite the existence of firm populations (Saleh et al., 2012 $2^{\mathrm{b}}$ ). The presence of both mating-type as detected by PCR based molecular markers are basically useful to identify the mating type locus in the field isolates of $M$. oryzae but not effective to identify the fertile $M$. oryzae strains because fertility is also influenced by genes other than the mating-type genes (Dayakar et al., 2000).

Using this assay, we determined the mating type of 97 isolates from different locations in south India, 46 isolates showed mating type allele MAT1-1 (Male fertile), 42 showed mating type MAT1-2 (Female fertile), 7 isolates showed hermaphrodite and 2 unknown mating type. The observation that both mating-types were present approximately in equal proportion in the population sampled from South India suggesting the possibility of sexual recombination in nature which can affect diversity and dissemination. Two isolates Mosi-15a from Mudegeri (Gamsali variety, Leaf blast) and Mo-si-88 from Bhavanisagar (Deluxe variety L.B) yielded no amplification consistently under standard conditions by using both MAT primers.

Several previous studies discussed about mating types in Magnaporthe oryzae, from various ecosystems of coastal Odisha, India. MAT1-1 mating type was dominating in all the ecosystems and MAT1-2 was found to be present in uplands as well as in irrigated fields. Both mating types could be found in the same field in irrigated ecosystem (Soma et al., 2014).

In the present study MAT1-2 and MAT1-1 were found to be present in both in irrigated and upland fields in Raichur and Uttara Kannada respectively. Where ever MAT1-1 and MAT1-2 are there we could expect 
variation in the $M$. oryzae population due to recombination. In addition presence of hermaphrodite $M$. oryzae isolates in a location clues the occurrence of wide diversity in its population. Distribution of both the mating type in the same field among field isolates of $M$. oryzae was recorded by earlier workers and suggested the possibility of occurrence of sexual recombination in nature (Kolmer et al., 1988; Kumar and Zeigler 1995).

Kumar et al. (1999) suggested possible occurrence of sexual recombination in $M$. oryzae population in Himalayan region. Imam et al. (2014) reported the presence of both mating types in North-East and Eastern India, of $63 \mathrm{M}$. oryzae isolates analysed, 16 of the isolates were of the mating type MAT1-1 while 35 were of the mating type MAT1-2 and eleven isolates did not produce a PCR product with either of these two mating types.

If a single mating-type predominates in a particular rice growing region, $M$. oryzae may not be sexually reproducing in that region and this may be important in the population dynamics of this pathogen. In past studies, MAT1-1 has been identified as the dominant mating-type associated with rice (Dayakar et al., 2000). The presence of only MAT1-1 in the pathogens is not uncommon as it was also detected in the M. oryzae population in Japan and other regions (Notteghem and Silué, 1992). In this study, it is interesting to note that, in few locations Viz., Mandya, Chikkamangalore, Koppal districts both MAT1-1 and MAT1-2 mating types and hermaphrodite isolates were present. This information draws our attention to study in detail about hostpathogen population in these locations. Hence, in these locations variations due to sexual recombination may be expected in nature. Clonal reproduction and sexual recombination may be the possible reasons for the population dynamics of M. oryzae in South India. Populations showing evidence for both types mating types may be assayed for fertility using a range of tester isolates from different regions. As locally obtained hermaphrodite isolates of both mating types from this study may be used as testers for a systematic survey of local field isolates in future.

\section{References:}

1. Bao-Huaa, W., Uo-Donga, L.G. and Hai-Minga, L. (2004): Assessment of Magnaporthe grisea mating type by PCR. J. Agri. Biotech., 12: 183-187.

2. Chao, C.T. and Ellingboe, A.H. (1991): Selection for mating competence in Magnaporthe grisea pathogenic to rice. Can. J. Bot., 69: 2130-2134.

3. Chengyun, L., Jiarui, L., Rui, S. and Yoshi-katsu, F. (1992): Cross-fertility of rice blast fungus Pyricularia oryzae. Southwest China J. Agric. Sci., 5:53-58.

4. Chuma, I., Isobe, C., Hotta, Y., Ibaragi, K., Futamata, N., Kusaba, M., Yoshida, K., Terauchi, R., Fujita, Y. and Nakayashiki, H. (2011): Multiple translocation of the Avr-Pita effector gene among chromosomes of the rice blast fungus Magnaporthe oryzae and related species. PLOS Pathog., 7:e1002147.

5. Consola, V.F., Cordo, C.A. and Salerno, G.L. (2005): Mating-type distribution and fertility status in Magnaporthe grisea populations from Argentina. Mycopathol., 160: 285-290.

6. Coppin, E., Debuchy, R., Arnaise, S., and Picard, M. (1997): Mating types and sexual development in filamentous ascomycetes. Microbiology and Molecular Biology Reviews, 61: 411.

7. Dayakar, B.V., Narayanan, N.N. and Gnanamanickam, S.S. (2000): Cross-compatibility and distribution of mating type alleles of the rice blast fungus Magnaporthe grisea in India. Plant Dis., 84: 700-704.

8. Devulapalle, K.S. and Suryanarayanan, S. (1995): Cross-incompatibility among Indian isolates of Pyricularia grisea. Plant Dis., 79: 779-781.

9. Dong-mei, L., Hong-Li, J. and Wen-de, L., (2005): Studies on mating types of Magnaporthe grisea in Sichuan Province of China. J. Sichuan Agri. Univ., 23: 15-16.

10. Hayashi, N., Li, C. and Li, J.L., (1997): In vitro production on rice plants of perithecia of Magnaporthe grisea from Yunnan, China. Mycol. Res., 101: 1308-1310.

11. Imam, J., Alam, S., Mandal, N.P., Dipankar Maiti, Variar, M., Shukla, P. (2014): Molecular Diversity and Mating Type Distribution of the Rice Blast Pathogen Magnaporthe oryzae in North-East and Eastern IndiaIndian J. Microbiol, DOI 10.1007/s12088-014-0504-6.

12. Itoi, S., Mishima, T., Arase, S., and Nozu, M. (1983): Mating behavior of Japanese isolates of Pyricularia oryzae. Phytopathology 73:155- 158.

13. Kang, S., Chumley, F.G. and Valent, B. (1994): Isolation of the mating-type genes of the phytopathogenic fungus Magnaporthe grisea using genomic subtraction. Genetics, 138(2): 289-296.

14. Kistler, H.C. and Miao, V.P.W. (1992): New Modes of Genetic Change in Filamentous Fungi. Ann. Review Phytopathol., 30: 131-152. 
15. Kolmer, J.A. and Ellingboe, A.H. (1988): Genetic relationships between fertility and pathogenicity and virulence to rice in Magnaporthe grisea. Can. J. Bot., 66: 891- 897.

16. Kolmer, J.A. and Ellingboe, A.H. (1988): Genetic relationships between fertility and pathogenicity and virulence to rice in Magnaporthe grisea. Can. J. Bot., 66: 891- 897.

17. Kumar, J. and Zeigler, R.S. (1995): Mating behavior of Magnaporthe grisea from central Himalayas of India. Phytopathol., 85: 1201.

18. Kumar, J., Nelson, R.J. and Zeigler, R.S. (1999): Population Structure and Dynamics of Magnaporthe grisea in the Indian Himalayas. Genetics, 152: 971-984 .

19. Leslie, J.F. and Klein, K.K. (1996): Female fertility and mating type effects on effective population size and evolution in filamentous fungi. Genetics, 144: 557-567.

20. Mekwatanakarn, P., Kositratana, W., Phromraksa, T. and Zeigler, R.S. (1999): Sexually fertile Magnaporthe grisea rice pathogens in Thailand. Plant Dis. 83: 939-943.

21. Metzenberg, R.L. and Glass, N.L. (1990): Mating Type and Mating Strategies in Neurospora. Bioessays, 12: 53-59.

22. Notteghem, J.L. and Silué, D. (1992): Distribution of the mating type alleles in Magnaporthe grisea populations pathogenic on rice. Phytopathology, 82:421-424.

23. Park, S.Y., Milgroom, M.G., Han, S.S., Kang, S. and Lee, Y.H. (2008): Genetic differentiation of Magnaporthe oryzae populations from scouting plots and commercial rice fields in Korea. Phytopathology, 98(4): 436-442.

24. Priyadarisini, V.B., Viji, G. and Gnanamanickam, S.S. (1999): Mating type distribution, fertility and pathogenicity of rice isolates of Magnaporthe grisea in four rice growing regions of India. Indian Phytopathol., $52: 28-34$.

25. Saleh, D., Milazzo, J., Adreit, H., Tharreau, D. and Fournier, E. $\left(2012^{\mathrm{a}}\right)$ : Asexual reproduction induces a rapid and permanent loss of sexual reproduction capacity in rice fungal pathogen Magnaporthe oryzae: results of in vitro experimental evolution assays. BMC Evol. Biol., 12: 42.

26. Saleh, D., Xu, P., Shen, Y., Li, C., Adreit, H., Milazzo, J., Ravigné, V., Bazin, E., Nottéghem, J.L., Fournier, E. and Tharreau, D. $\left(2012^{\mathrm{b}}\right)$ : Sex at the origin: an Asian population of the rice blast fungus Magnaporthe oryzae reproduces sexually. Mol. Ecol., 21(6): 1330-1344.

27. Soma, S., Urmila, D., Shubhransu, N., Behera, L. and Mukherjee, A.K. (2014): Mating Types Analysis of Magnaporthe oryzae Populations by Molecular Methods The Open Biotechnol. J., 2014, 8: 6-12.

28. Takan, J.P., Chipili, J., Muthumeenakshi, S., Talbot, N.J., Manyasa, E. O., Bandyopadhyay, R., Sere, Y., Nutsugah, S.K., Talhinhas, P., Hossain, M., Brown, A.E. and Sreenivasaprasad, S. (2011): Magnaporthe oryzae populations adapted to finger millet and rice exhibit distinctive patterns of genetic diversity, sexuality and host interaction. Mol. Biotechnol., 10.1007/s12033-011-9429.

29. Valent, B., Crawford, M.S., Weaver, C.G. and Chumley, F.G. (1986): Genetic studies of fertility and pathogenicity in Magnaporthe grisea (Pyricularia oryzae). Iowa State J. Res., 60: 569-594.

30. Valent, B., Farrall, L. and Chumley, F.G. (1991): Magnaporthe grisea genes for pathogenicity and virulence identified through a series of backcrosses. Genetics, 127: 87-101.

31. Viji, G. and Gnanamanickam, S.S. (1998): Mating type distribution and fertility status of Magnaporthe grisea populations from various hosts in India. Pl. Dis., 82: 36-40.

32. Wang, B.H., Lu, G.D., Li, H.M., Lin, Y. and Wang, Z.H. (2004): Aaaessment of Magnaporthe grisea mating type by PCR (in Chinese). J. Agri. Biotechnol. $12: 183-187$.

33. www.intechopen.com, Klaus, Brazil - Magnaporthe oryzae Genetic Diversity and Its Outcomes on the Search for Durable Resistance.

34. Yaegashi, H. and Nishihara, N. (1976): Production of the perfect stage in Pyricularia from cereals and grasses. Ann. Phytopathol. Soc. Jpn. 42:511-515.

35. Zeigler, R.S. (1998): Recombination in Magnaporthe grisea. Annu. Rev. Phytopathol., 36: 249-275.

36. Zeigler, R.S., Leong, S.A. and Teng, P.S. (1994): A proposal for linking blast population analysis to resistance breeding. Rice Blast Disease. CAB International, Wallingford, Oxon, UK.

37. Zeigler, R.S., Scott, R.P., Leung, H., Bordeos, A.A., Kumar, J. and Nelson, R.J. (1997): Evidence of parasexual exchange of DNA in the rice blast fungus challenges its exclusive clonality. Phytopathology, 87: 284-294.

38. Zeng, J., Feng, S., Cai, J., Wang, L., Lin, F. and Pan, Q. (2009): Distribution of mating type and sexual status in Chinese rice blast populations. Pl. Dis., 93:238-242.

39. Zheng, Y., Zhang, G. and Lin, F. (2008): Development of microsatellite markers and construction of genetic map in rice blast pathogen Magnaporthe grisea. Fungal Genet. Biol., 45: 1340-1347. 